\title{
Helicobacter Pylori Infection in Gross and Microscopic type of Gastric Adenocarcinoma; a Comparative Study
}

\author{
Nazia $\mathbf{Q}^{1}$, Sadia $\mathrm{S}^{2}$, Raheela $\mathrm{A}^{3}$, Hina $\mathrm{K}^{2}$ and Muhammad Faisal $\mathrm{F}^{4 *}$ \\ ${ }^{1}$ Department of Pathology, Al-Tibri Medical College and Hospital, Pakistan \\ ${ }^{2}$ Department of Anatomy, Al-Tibri Medical College and Hospital, Pakistan \\ ${ }^{3}$ Department of Physiology, Al-Tibri Medical College and Hospital, Pakistan \\ ${ }^{4}$ Department of Research \& Development (R\&D), Al-Tibri Medical College and Hospital, Pakistan
}

Submission: November 27, 2017; Published: January 19, 2018

*Corresponding author: Muhammad Faisal Fahim, M.Sc(Statistics), Statistician, Research \& Development Department, Al-Tibri Medical College and Hospital, Isra University Karachi-Pakistan, Tel: 0092-346-3160827; Email: faisalfahim88@hotmail.com

Abstract

Objective: To compare the association of helicobacter Pylori (H.pylori) infection in Gross and Microscopic type of gastric adenocarcinoma patients attending a tertiary care hospital in Karachi.

Material \& methods: This was a Comparative, cross sectional study carried out at Al-Tibri medical college Karachi in collaboration with Diagnostic and research Lab (DDRL) from Feb 2015 to Sep 2015. This study integrated 92 gastric tissues in which 79 were gastric adenocarcinoma tissue and 13 were control sample taken from sleeve gastrectomy. For gross morphology of gastric carcinoma, the gross types were divided into four types, fungating, Ulcerative, infiltrating and polypoid and it was divided into two groups Nondependent H.pylori and dependent H.pylori gastric carcinoma. For Microscopic type of gastric carcinoma, the tumor was divided into Diffuse and Intestinal type and it was further divided into two groups: Nondependent H.Pylori and dependent H.pylorigastric carcinoma. SPSS was used to analyze the data.

Results: Gross morphology and microscopic type of gastric carcinoma showed an insignificant P-value of 0.443 which shows that there was no significant difference found between these two parameters. The relation between the dependent H.pylori in gross morphology of gastric carcinoma and nondependent H.pylori in microscopic type of gastric carcinoma the P-value was found to be 0.52 shows no significant difference and the relation between dependent and nondependent H.pylori in microscopic type of gastric carcinoma the P-value was found to be 0.771 shows no significant difference.

Conclusion: Grossly the ulcerated type and microscopically the intestinal type was significantly present in dependent H.pylori gastric carcinoma but there was no association found between gross and microscopic type of dependent H.pylori gastric carcinoma.

Keywords : Gastric carcinoma; Helicobacter pylori; Sleeve gastrectomy

Abbreviations: H pylori: Helicobacter Pylori; DUHS: Dow University of Health Sciences; DDRL: Dow Diagnostic and Research Lab; SPSS: Statistical Package for Social Sciences

\section{Introduction}

Gastric cancer represents a major clinical problem, linked with considerable morbidity and mortality [1]. Gastric cancers are diagnosed every year with 1 Million cases reported and it is the 4 th most leading cause of death worldwide. Gastric cancer is the 2 nd leading cause of cancer related death and approximately 700,000 of people surrender their life because of carcinoma stomach [2]. Gastric cancer is uncommon before the age of 40, but its frequency gradually increase thereafter and peaks in the seventh decade of life [3]. The distinct geographic disparity, time trends and the migratory effect on the gastric cancer incidence recommend that environmental or lifestyle factors are major contributors to the etiology of disease [4]. Previous to the discovery of the organism, it was recognized that gastric adenocarcinomas characteristically arose in areas of gastritis. When the association between H. pylori and chronic gastritis was established, investigators began to take interest in the contributory role of $\mathrm{H}$. pylori in gastric cancer. The first studies to examine the association between $\mathrm{H}$. pylori and gastric cancer 
were ecological, comparing the regional frequency of $\mathrm{H}$. pylori with the occurrence of gastric cancer [5]. Helicobacter pylori may generate an atmosphere which is highly positive to produce carcinogenesis and share with other life style and environmental exposures.

There is an evidence that consumption of salty foods and $\mathrm{N}$-nitroso compound and low intake of fresh fruits and vegetable augment the threat of gastric cancer. Helicobacter pylori gastritis support the growth of nitrosating bacteria which catalyze the production of carcinogenic N-nitroso compound [6]. An area of the world with a low prevalence of $\mathrm{H}$. pylori infection tend to have a comparatively low frequency of gastric cancer, but geographic disparity in gastric cancer rates cannot be explained exclusively by variations in H. pylori prevalence. For example, populations in many parts of Africa and India have a high prevalence of $\mathrm{H}$. pylori infection but a relatively low incidence of gastric cancer [7]. H. pyloricolonizes the stomach and educes a gastric mucosal inflammatory response termed "gastritis" in both humans and experimentally infected animals. Once recognized in the human stomach, H. pylori and gastric inflammation can persevere for many decades in the lack of antimicrobial treatment. Longitudinal studies point out that gastritis is one of the first noticeable changes in a stepwise pathway of histologic abnormalities that can eventually terminate in gastric cancer: inflammation, gastric atrophy (loss of specialized cell types such as parietal cells and chief cells), intestinal metaplasia (presence of intestinal-type epithelium in the stomach) and dysplasia $[8,9]$.

Grossly, the carcinoma of stomach has wide distinction: polypoid tumor (type I), Fungating tumor (Type II), Ulcerated tumor (Type III), Deeply invasive tumor (Type IV). Fungating tumor grow mainly into lumen, plane, ulcerated and severely invasive tumor develop largely all the way through the wall of stomach [10]. Microscopically, WHO describe gastric carcinoma into: Adenocarcinoma (Intestinal \& Diffuse) Papillary, Tubular adenocarcinoma, Mucinous adenocarcinoma, signet ring cell carcinoma, squamous cell carcinoma [11]. The present study was designed to compare the frequency of H.pylori infection in gross and microscopic type of gastric carcinoma in a tertiary care hospital of Karachi.

\section{Material and Methods}

This was a comparative cross sectional study with Nonprobability convenient sampling technique conducted in Dow Diagnostic and research Lab (DDRL) in association with Al-Tibri medical college Karachi from February to September 2015. A total of 92 gastric tissue samples were examined along with Informed consent and Clinical biodata of patients. The study was approved by the Ethical committee of Dow University of health sciences (DUHS) and Isra University Hyderabad Sindh. Overall 92 gastric adenocarcinoma samples were selected in this study. In the frequency of gross types of gastric carcinoma, we found only 16 large biopsy samples out of 79 samples, the rest of 63 samples were small biopsy samples. Therefore, gross morphological classification was possible only on these 16 samples. The sample size was calculated using an online tool where power of study was set at 80 , confidence level was $95 \%$ and margin of error was kept at $5 \%$.Patients who had a history of gastrointestinal symptoms with clinical support of Gastric cancer were selected regardless of age and gender, resection specimen as well as gastric cancer biopsies along with this for control samples, sleeve gastrectomy specimen were selected from the patient who had a history of obesity, regardless of age and gender.

Biopsies of tissue taken from cardiac region and post chemotherapeutic carcinoma were excluded. To compare the gross types of gastric adenocarcinoma with microscopic type of gastric adenocarcinoma, the samples were divided into two groups, (according to Lauren and WHO classification), microscopically the tumors divided into two Intestinal type and diffuse type and macroscopically (Borman classification) dividing it into four Type I polypoidy, type II Fungating, Type III ulcerated, type IV Infiltrating. The samples were further divided into two groups dependent helicobacter pylori gastric adenocarcinoma and non-dependent helicobacter pylori gastric adenocarcinoma. Biopsy samples were examined grossly and microscopically. Biopsy materials were fixed in $10 \%$ neutral buffered formalin, embedded in paraffin and $5 \mu \mathrm{m}$ sections were set for biopsy materials and they were cut to perform subsequent staining [12]. H\&E, Giemsa Stain (for H.pylori) were the staining techniques used for staining the slides for histopathological examinations [13].

\section{Statistical analysis}

Data analysis was done using statistical package for social sciences (SPSS) version 20.0. All Categorical Variables were expressed in frequency and percentage and continuous variables were stated as Mean and standard deviation Chi square test was used to assess the association between the variables. P value of $\leq 0.05$ was taken as statistically significant.

\section{Results}

In the total of 92 gastric tissue samples, of these $79 \%$ samples were from gastric carcinoma while total $13 \%$ were control samples. In these $79 \%$ cases $63.3 \%$ were males and $36.7 \%$ were females. To compare the relation between gross type of gastric carcinoma and microscopic type of gastric adenocarcinoma we found that intestinal type of gastric carcinoma was present in $11.3 \%$ in ulcerated type of gastric carcinoma, 3.8\% in Fungating type, $3.8 \%$ in Invasive type of gastric carcinoma and no intestinal type was found in Polypoid type of gastric carcinoma.81.1\% Intestinal type and $76.9 \%$ diffuse type was present in small biopsy sample. In other type of microscopic gastric carcinoma that is diffuse type we found that $11.5 \%$ was found in ulcerated type, $11.5 \%$ in fungating type and no tumor type found in invasive and polypoid type. The P-value was found to be 0.443 which shows that there is no significant difference noted between these variables (Table 1). On the other hand if we compare the 
frequency of Helicobacter pylori between the gross morphology of gastric carcinoma we found that $12.7 \%$ Dependent H.pylori was present in ulcerated type of gastric carcinoma, $7.0 \%$ was found in Fungating type of Gastric carcinoma and 2.8\% was found in Invasive type of Gastric carcinoma. 77.5\% dependent H.pylori gastric carcinoma was present in small biopsy sample. So the P-Value was found to be 0.52 which shows that there is no significant difference between these two variables (Table
2). In microscopic type of Gastric carcinoma, $62.5 \%$ intestinal type were found in non-dependent H.pylori gastric carcinoma and $37.5 \%$ were found in Diffuse type of gastric carcinoma. $67.6 \%$ intestinal type were found in dependent H.pylori gastric carcinoma and $32.4 \%$ diffuse type were found in dependent H.pylori gastric carcinoma. The P-Value was found to be 0.771 , shows non-significant difference (Table 3).

Table 1: Association of Gross type (Macroscopic) with Microscopic type of Cancer.

\begin{tabular}{|c|c|c|c|c|c|c|}
\hline \multirow{2}{*}{$\begin{array}{l}\text { Type of Cancer } \\
\text { (Microscopic) }\end{array}$} & \multicolumn{3}{|c|}{ Gross Type / Macroscopic } & \multirow[b]{2}{*}{ Invasive } & \multirow{2}{*}{ Total } & \multirow{2}{*}{ P-value } \\
\hline & Small Biopsy & Ulcerated & Fungating & & & \\
\hline \multirow[t]{2}{*}{ Intestinal } & 43 & 6 & 2 & 2 & 53 & \multirow{6}{*}{0.443} \\
\hline & $81.10 \%$ & $11.30 \%$ & $3.80 \%$ & $3.80 \%$ & $100.00 \%$ & \\
\hline \multirow[t]{2}{*}{ Diffuse } & 20 & 3 & 3 & 0 & 26 & \\
\hline & $76.90 \%$ & $11.50 \%$ & $11.50 \%$ & $0.00 \%$ & $100.00 \%$ & \\
\hline \multirow{2}{*}{ Total } & 63 & 9 & 5 & 2 & 79 & \\
\hline & $79.70 \%$ & $11.40 \%$ & $6.30 \%$ & $2.50 \%$ & $100.00 \%$ & \\
\hline
\end{tabular}

Table 2: Association of Macroscopic type of cancer with groups.

\begin{tabular}{|c|c|c|c|c|c|c|}
\hline \multirow{2}{*}{ Group } & \multicolumn{3}{|c|}{ Gross type/Macroscopic } & \multirow{2}{*}{ Total } & \multirow{2}{*}{ P-value } \\
\cline { 2 - 6 } & Small biopsy & Ulcerated & Fungating & Invasive & 8 \\
\hline Non-Dependent & 8 & 0 & 0 & 0 & $100.00 \%$ \\
\hline & $100.00 \%$ & $0.00 \%$ & $0.00 \%$ & $0.00 \%$ & 71 \\
\hline Dependent & 55 & 9 & 5 & 2 & $100.00 \%$ \\
\hline & $77.50 \%$ & $12.70 \%$ & $7.00 \%$ & $2.80 \%$ & 79 \\
\hline
\end{tabular}

Table 3: Association of Microscopic type of cancer with groups.

\begin{tabular}{|c|c|c|c|c|}
\hline \multirow{2}{*}{ Group } & \multicolumn{2}{|c|}{$\begin{array}{c}\text { Type of Cancer } \\
\text { (Microscopic) }\end{array}$} & \multirow{2}{*}{ Total } & \multirow{2}{*}{ P-value } \\
\cline { 2 - 4 } & Invasive & Diffuse & & \\
\hline \multirow{2}{*}{$\begin{array}{c}\text { Non- } \\
\text { Dependent }\end{array}$} & 5 & 3 & 8 & \multirow{2}{*}{0} \\
\cline { 2 - 4 } & $62.50 \%$ & $37.50 \%$ & $100.00 \%$ & \multirow{2}{*}{0.771} \\
\hline \multirow{2}{*}{ Dependent } & 48 & 23 & 71 & \\
\cline { 2 - 4 } & $67.60 \%$ & $32.40 \%$ & $100.00 \%$ & \\
\hline \multirow{2}{*}{ Total } & 53 & 26 & 79 & \\
\cline { 2 - 4 } & $67.10 \%$ & $32.90 \%$ & $100.00 \%$ & \\
\hline
\end{tabular}

\section{Discussion}

Gastric Cancer is the 4th most frequently diagnosed cancer and it is the second most frequent cause of cancer related death worldwide [2,14]. Gastric carcinogenesis is a multifactorial process in which several factors are involved, some milieu lesions are also present, these lesions provide prospect to decrease the mortality rate of gastric carcinoma by earlier recognition of these lesions [15]. Helicobacter pylori is a gram negative bacterium currently colonize the human stomach and also have been the centre of basic biochemical and clinical research since its innovation [16]. This study compare the association of H.pylori infection in gross and Microscopic type of Gastric adenocarcinoma and according to our study there is no significant difference noted between the presence of H.pylori infection in gross and microscopic type of gastric adenocarcinoma. In our study, grossly the ulcerated type was present in high frequency. In a previous study of USA report that the most common macroscopic type of gastric carcinoma was fungating tumor $36 \%$ and ulcerated was $25 \%$, infiltrating $26 \%$ and polypoid was $7 \%$ [10]. Our study also reveals the presence of intestinal type of gastric carcinoma is more common as compare to diffuse type. Another study from Karachi Pakistan also report that intestinal type was more common than diffuse [17]. A retrospective study from USA determined the frequency of Helicobacter pylori in Intestinal type gastric carcinoma was $89 \%$ as compare to diffuse which was $31.8 \%$ [18]. Another study reported the reason for increase in frequency of intestinal type of gastric carcinoma was often associated Intestinal metaplasia and presence of helicobacter pylori infection [19]. In our study, grossly the ulcerated type and microscopically the intestinal type were significantly present in dependent helicobacter pylori gastric carcinoma but there is no association found between gross and microscopic type of gastric carcinoma. Another study 
reveals grossly type I lesion (protruding type) and type IIa lesion (superficial elevated) are likely to represent intestinal type whereas diffuse type are likely to be type IIc (superficial depressed) or type III (excavated or Ulcerated) lesions [20]. The reason could be the selected cases diagnosed in advanced stages so grossly the lesion was ulcerated and in our society the increase in the frequency of intestinal type was due to the influence of environmental factors, poor hygiene, overcrowding and low socio economic status can lead to development of $\mathrm{H}$ pylori and due to this it can progress to intestinal type of gastric carcinoma.

\section{Conclusion}

Grossly the ulcerated type and microscopically the intestinal type was significantly present in dependent H.pylori gastric carcinoma but there was no association found between gross and microscopic type of dependent H.pylorigastric carcinoma.

\section{References}

1. Papavassilliou ED, Savva S (2008) Gastritis and Gastric Cancer: Time for gastric cancer prevention. Annals of Gastroenterology 21(4): 218222.

2. Parkin DM, Bray FI, Devesa SS (2001) Cancer burden in the year 2000. The global picture. Eur J cancer 37(8): 44-66.

3. Gore R (1997) Gastrointestinal cancer. Radiol Clin North Am 35(2): 295-310.

4. Katherine DC, Alfred IN (2006) Epidemiology of Gastric cancer. World J Gastroenterol 12(3): 354-362.

5. Herrara V, Personnate J (2009) Helicobacter pylori and gastric adenocarcinoma. Clin Microbiol Infect 15(11): 971-976.

6. Sanduleanu S, Jonkers D, De Bruine A, Hameeteman W, Stockbrugger RW (2001) Non Helicobacter pylori bacterial flora during acid suppressive therapy: differential findings in gastric juice and gastric mucosa. Aliment Pharmacol Ther 15(3): 379-388.

7. De Martel C, Forman D, plummer M (2013) Gastric cancer epidemiology and risk factors. Gastroenterol clin North Am 42(2): 219-240.
8. Peek RM, Blaser MJ (2002) Helicobacter pylori and gastrointestinal tract adenocarcinoma. Nat rev Cancer 2(1): 28-37.

9. Fox JG, wang TC (2007) Inflammation, atrophy and gastric cancer.J Clin invest 117:60-69.

10. Sun ML, Kyoung MK, Jae YR (2013) Gastric Carcinoma: Morphologic Classifications and Molecular changes. InTech 42: 129.

11. Berlth F, Bollschweiler E, Drebber U, Hoelscher AU, Moenig S (2014) Patho histological classification systems in gastric cancer: Diagnostic relevance and prognostic value. World J Gastroenterol 20(19): 56795684 .

12. Qamar S, Bukhari M, Asrar A, Sarwar S, Niazi S (201) Evaluation of Antral Gastric Biopsies .A study of 50 patients at Mayo Hospital. Special Edition Annals 16(1): 45-50.

13. Parkin DM (2004) International variation. Oncogene 23(38): 63296340.

14. Ferlay J, Shin HR, Bray F, Forman D, Mathers C, et al. (2010) Estimates of worldwide burden of cancer in 2008:GLOBOCAN 2008.Int J cancer 127(12): 2893-28917.

15. Haroon S, Faridi N, Lodhi FR. Mujtaba S (2013) Frequency of precancerous lesions in endoscopic Gastritis Biopsies in Chronic Gastritis. J Coll Physicians Surg Pak 23(4): 247-250.

16. Mohammad JS, Zaidi SF, Sugiyama T (2012) Epidemiological Ins and Outs of Helicobacter pylori: A review. J Pak Med Assoc 62(9): 955-959.

17. Muhammad A, Syed S (2007) Association of helicobacter pylori with carcinoma of stomach. Pak Med Assoc 57(7): 337-341.

18. Parsonnet J, Vandersteen D, Goaates J, Sibley RK, Pritikin J, et al. (1991) Helicobacter pylori infection in intestinal and Diffuse type gastric carcinoma. J Natl Cancer Inst 83(9): 640-643.

19. Kaneko S, Yoshimura T (2001) Time trend analysis of gastric cancer incidence in Japan by histological types 1975-1989. Br J Cancer 84(3): 400-405.

20. Hu B, El Hajj N, Sittler S, Lammert N, Barnes R, et al. (2012) Gastric cancer: Classification, histology and application of molecular pathology. J Gastrointestinal oncol 3(3): 251-261.

\section{Your next submission with Juniper Publishers} will reach you the below assets

- Quality Editorial service

- Swift Peer Review

- Reprints availability

- E-prints Service

- Manuscript Podcast for convenient understanding

- Global attainment for your research

- Manuscript accessibility in different formats

( Pdf, E-pub, Full Text, Audio)

- Unceasing customer service

Track the below URL for one-step submission https://juniperpublishers.com/online-submission.php 